\title{
PARÂMETROS DE TEXTURA EM QUEIJOS PROCESSADOS: INFLUÊNCIA DA UTILIZAÇÃO DE CONCENTRADOS PROTEICOS DE LEITE E DE SORO
}

\section{Texture profile in processed cheese: influence of the use of milk protein concentrates and whey protein concentrates}

\author{
Alisson Borges de Souza ${ }^{{ }^{*}}$, Luiz Carlos Gonçalves Costa Júnior ${ }^{2}$, Ítalo Tuler Perrone ${ }^{3}$, \\ Rodrigo Stephani ${ }^{1}$, Débora de Freitas Almeida ${ }^{1}$
}

\section{RESUMO}

As propriedades tecno-funcionais das proteínas, relacionadas a várias características moleculares gerais são favorecidas por desdobramento parcial das estruturas. Destas interações, o pH do meio apresenta-se como um grande interferente na intensidade e tipo de interação ocorrida. Assim, este trabalho teve como objetivo avaliar tecnologicamente a influência de diferentes proporções de concentrado proteico de soro/concentrado proteico de leite no perfil de textura de queijos processados em diferentes valores de $\mathrm{pH}$. Foram analisadas amostras comerciais de concentrado proteico de soro (WPC) e concentrado proteico de leite (MPC) na proporção de $112,5 \mathrm{~g} / \mathrm{kg}$ de queijo processado. Foi realizado o ajuste do $\mathrm{pH}$ no momento inicial e no momento final da fabricação, além de um tratamento onde não foi adicionado ácido. Os resultados foram interpretados em função dos atributos de textura: dureza, elasticidade e adesividade. Maiores proporções de concentrado proteico de soro influenciaram de forma mais drástica na dureza. Por outro lado, maiores proporções de concentrado proteico de leite na formulação do queijo processado alteraram de forma mais positiva a elasticidade e adesividade. A alteração do $\mathrm{pH}$ nos queijos processados que utilizam concentrados proteicos modifica as características de dureza e adesividade desses produtos.

Palavras-chave: $\mathrm{pH}$, proteínas lácteas, processamento, perfil de textura.

1 Gemacom Tech, Rua Bruno Simili, 380, Distrito Industrial, 36092-050, Juiz de Fora, MG, Brasil. E- mail: alissonborgesdesouza@hotmail.com

2 Empresa de Pesquisa Agropecuária de Minas Gerais, Instituto de Laticínios Cândido Tostes (EPAMIG/ ILCT), Juiz de Fora, MG, Brasil.

3 Universidade Federal de Viçosa (UFV), Departamento de Tecnologia de Alimentos (DTA), Viçosa, MG, Brasil.

* Autor para correspondência. 


\begin{abstract}
The techno-functional properties of proteins related with the molecular characteristics are facilitated by partial unfolding of structures. From these interactions, the medium $\mathrm{pH}$ is presented as a major interferer in intensity and type of reaction that takes place. The intensity of denaturation and interaction of different proteins occur in different forms and intensity accordingly to the $\mathrm{pH}$ value of the medium in which they are located. This study aimed to verify the influence of interactions between whey protein concentrate/milk protein concentrate on the evolution of the texture profile of processed cheese at different $\mathrm{pH}$ values. We have analyzed samples of commercial whey protein concentrate (WPC) and milk protein concentrate (MPC) using $112.5 \mathrm{~g} / \mathrm{kg}$ processed cheese. The results were interpreted in terms of texture profile. It was also possible to optimize the different proportions of WPC and MPC, and $\mathrm{pH}$ value change the parameters of texture for creamy processed cheese and the $\mathrm{pH}$ was also an influencing factor in this optimization.
\end{abstract}

Keywords: $\mathrm{pH}$; dairy protein; processing; texture profile.

\section{INTRODUÇÃO}

Os benefícios das proteínas do leite como ingredientes em outros alimentos originam de suas excelentes propriedades nutricionais e na capacidade de contribuir para propriedades tecno-funcionais, sensoriais e reológicas nos produtos finais. Entretanto, essas propriedades não costumam ser entendidas com detalhes suficientes que permitam que a estrutura proteica alcance um melhor desempenho (SINGH, 2009).

$\mathrm{O}$ entendimento das interações envolvidas e a avaliação do efeito das proteínas lácteas como ingrediente industrial, ainda carece de maior número de trabalhos. É necessário o desenvolvimento de uma melhor adequação da utilização destas proteínas dentro de cada perfil tecnológico desejado nas diversas linhas de processamento (ANEMA, 2008). O entendimento da interação das proteínas lácteas proporciona às indústrias alimentícias a obtenção de uma relação adequada com um melhor custo/benefício na utilização de cada tipo de proteína dentro das características desejadas no produto final. Como consequência, a indústria pode disponibilizar ao mercado produtos que utilizam proteínas de elevado valor biológico como ingredientes tecnológicos.

Diante destas interações, o pH do meio apresenta-se como um grande interferente na intensidade e no tipo de reação ocorrida. A variação do $\mathrm{pH}$ altera a intensidade de desnaturação e a interação das diferentes proteínas e influencia no produto final. Este trabalho teve como objetivo avaliar tecnologicamente a influência de diferentes proporções de concentrado proteico de soro/ concentrado proteico de leite no perfil de textura de queijos processados em diferentes valores de $\mathrm{pH}$.

\section{MATERIAL E MÉTODOS}

\section{Amostras dos concentrados proteicos desidratados}

Foram selecionados dois tipos de concentrados proteicos desidratados para avaliação: Concentrado Proteico de Leite (MPC 70) e Concentrado Proteico de Soro 
(WPC 70). Os critérios de escolha foram definidos em ordem de importância: uso industrial no Brasil, importância econômica atual, amplitude de utilização em diferentes áreas e prospecção de utilização futura. Ambos os produtos utilizados foram provenientes de unidades produtoras sediadas nos Estados Unidos da América (EUA). Os produtos foram gentilmente adquiridos e fornecidos pela empresa Gemacom Tech.

\section{Caracterização físico-química}

Os produtos foram analisados em duplicata no Laboratório de Pesquisa do Instituto de Laticínios Cândido Tostes da Empresa de Pesquisa Agropecuária de Minas Gerais - EPAMIG e no Laboratório de Pesquisa Desenvolvimento e Inovação da Gemacom Tech, ambos em Juiz de Fora, MG. Nos concentrados proteicos foram realizadas análises dos teores de gordura, proteína, resíduo mineral fixo (cinzas), lactose, umidade e concentração de proteína em base seca, e $\mathrm{pH}$. Para os queijos processados foram realizadas análises de teores de gordura, proteína, umidade e $\mathrm{pH}$. As metodologias analíticas foram conduzidas conforme procedimentos descritos pela AOAC (2005), excetuando as análises de proteína em base seca e lactose que foram determinadas por cálculo. A determinação do teor de lactose foi realizada através da subtração do teor de gordura, proteína total e resíduo mineral fixo do teor de sólidos totais.

\section{Fabricação dos queijos processados}

Foram realizadas fabricações de queijos processados em duplicata, de acordo com a formulação descrita na Tabela 1 , na qual foram aplicados quatro tratamentos com diferentes proporções de concentrados proteicos de leite e soro. Esses concentrados foram aplicados no processamento do queijo processado, em três condições diferentes: Tratamento $1\left(\mathrm{~T}_{1}\right)$ : Controle de $\mathrm{pH}$ por meio da adição de ácido cítrico $(99 \% \mathrm{~m} / \mathrm{m})$ no início da fabricação; Tratamento $2\left(\mathrm{~T}_{2}\right)$ : sem adição de ácido cítrico para controle do $\mathrm{pH}$ final do produto; e Tratamento $3\left(\mathrm{~T}_{3}\right)$ : adição de ácido cítrico $(99 \% \mathrm{~m} / \mathrm{m})$ para controle do $\mathrm{pH}$ final no momento do término do processamento (Figura 1).

Foram adicionados $2 \mathrm{~g}$ de ácido cítrico nos tratamentos 1 e 3 para obtenção do $\mathrm{pH}$ final de 5,6 desejado para este tipo de produto, conforme descrição completa apresentada na Figura 1.

A massa láctea foi produzida a partir de leite desnatado por coagulação ácida. A massa foi padronizada para obtenção de um teor de $9 \%(\mathrm{~m} / \mathrm{m})$ de proteína e $25 \%(\mathrm{~m} / \mathrm{m})$ de sólidos totais.

O processamento foi realizado em equipamento de aquecimento indireto e alta

Tabela 1 - Formulação dos Queijos Processados

\begin{tabular}{lc}
\hline \multicolumn{1}{c}{ Ingredientes } & Quantidade $(\mathrm{g})$ \\
\hline Creme de Leite $(36 \%$ de teor de gordura) & 500 \\
Massa Láctea & 255 \\
WPC/MPC & 112,5 \\
Citrato de Sódio $(99 \% \mathrm{~m} / \mathrm{m})$ & 10 \\
Tripolifosfato de sódio & 6,4 \\
Água & 111,1 \\
Cloreto de Sódio $(99,9 \% \mathrm{~m} / \mathrm{m})$ & 3 \\
\hline
\end{tabular}


rotação, Thermomix, da empresa Vorwerk. Todos os ingredientes foram adicionados no início da fabricação, o aquecimento foi realizado à $90{ }^{\circ} \mathrm{C}$ por 3 minutos, exceto no tratamento 3 , no qual o ácido cítrico foi adicionado após atingir a temperatura de $90{ }^{\circ} \mathrm{C}$. A rotação utilizada variou entre 4.000 a 5.000 rpm. Os queijos processados foram embalados e mantidos sob refrigeração a $5^{\circ} \mathrm{C}$ para análise de textura após 24 horas.

\section{Análise de perfil de textura}

O perfil de textura foi obtido por teste de dupla compressão das amostras de queijo processado em analisador de textura CT3 (Brookfield). As condições utilizadas nos ensaios foram: Análise do Perfil de Textura (TPA); velocidade de teste: $1,0 \mathrm{~mm} / \mathrm{s}$; distância de compressão: $10 \mathrm{~mm}$; força mínima de contato: $10,0 \mathrm{~g}$; probe utilizada: cilindro de acrílico de altura: $20 \mathrm{~mm}$ e diâmetro: $40 \mathrm{~mm}$. Este método foi utilizado após avaliação da melhor configuração para avaliação dos produtos em questão. Os dados foram coletados no programa "TexturePro CT V1.2".

Foram analisados os atributos dureza, adesividade e elasticidade. Para cada tratamento foram realizados ensaios em duplicata.

\section{Análise estatística dos dados}

Os resultados obtidos no teste de perfil de textura foram analisados por meio da aplicação do coeficiente de correlação e regressão. Foram conduzidas análises de variância (ANOVA) a fim de testar as diferenças nas variáveis estudadas em relação à proporção de concentrados proteicos e forma de ajuste do $\mathrm{pH}$ final do produto. $\mathrm{O}$ teste de médias Tukey também foi utilizado para definição do nível de significância da variação entre os tratamentos. Empregou-se o programa SISVAR versão 5.3 para a execução das análises estatísticas (FERREIRA, 2000).

Para a análise de regressão e correlação foram aceitos os modelos que apresentaram nível de significância igual ou menor que 5\%.

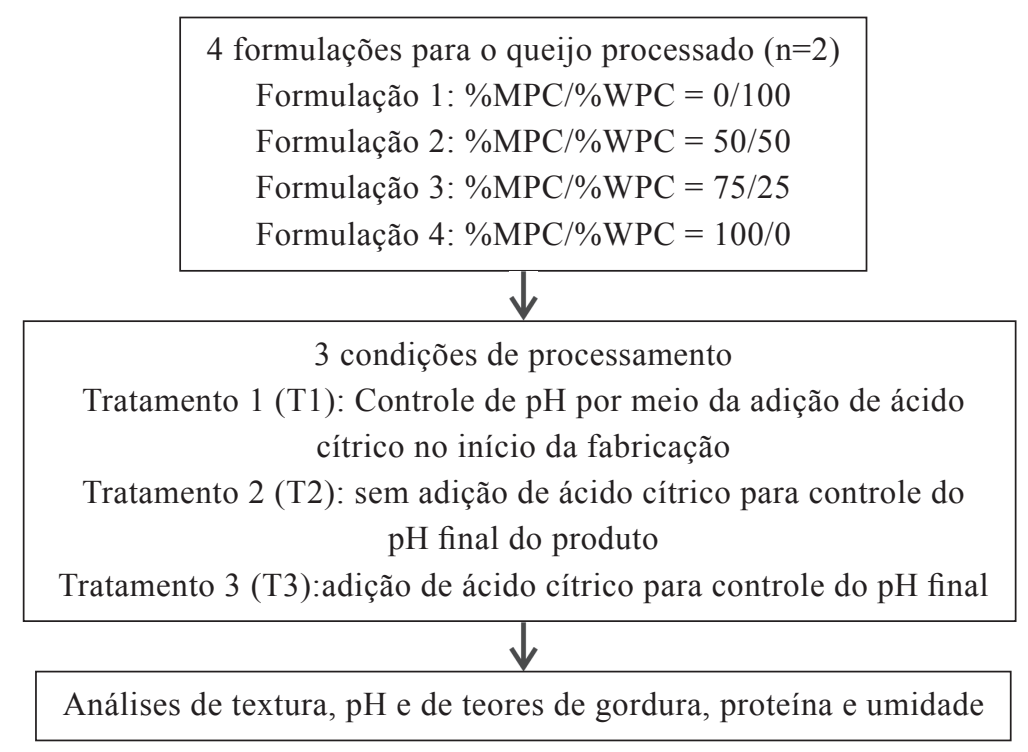

Figura 1 - Descrição dos tratamentos realizados durante experimento 


\section{RESULTADOS E DISCUSSÃO}

\section{Caracterização físico-química dos concen- trados proteicos e dos queijos processados}

Os teores de proteína, gorduras totais, umidade, lactose, resíduo mineral fixo e o $\mathrm{pH}$ dos concentrados proteicos utilizados nas produções de queijos processados (Tabela 2), apresentaram-se condizentes aos dados da bibliografia apresentados por Singh (2009).

O WPC e o MPC utilizados neste estudo foram de alto teor proteico (variando de 643,6 g.kg-1 a 652,9 g. $\mathrm{kg}^{-1}$ ), por possuírem teor de proteína superior a $60 \%$ conforme definido por Singh (2009).

Houve correta padronização da formulação utilizada, o que propiciou comparação direta entre os tratamentos nas análises de textura (Tabela 3 ).

Os resultados apresentados indicam que os requisitos físico-químicos foram atendidos conforme Regulamento Técnico de Identidade e Qualidade de Queijos Processados, no qual são estabelecidos teor de umidade máximo de 70 g. $100 \mathrm{~g}^{-1}$ e gordura no extrato seco mínimo de 35 g. $100 \mathrm{~g}^{-1}$ (BRASIL, 1997).

Com a determinação do teor de umidade de cada produto, foi possível utilizar uma quantidade fixa de sólidos totais empregado em cada ensaio, eliminando assim a possibilidade de variação causada por diferentes teores de umidade.

A proteína na base seca é uma forma mais usual de trabalho com os concentrados proteicos, devido à característica de higroscopicidade dos concentrados e evita a possibilidade de erro analítico devido ao ganho de umidade, e consequentemente, de massa do produto e diminuição percentual no teor de proteína total.

\section{Avaliação do impacto dos concentrados proteicos de soro e leite em diferentes pro- porções na textura de queijos processados}

Após produções dos queijos processados, os mesmos foram refrigerados por um prazo de 24 horas, e assim foram realizadas as análises de textura apresentadas na Tabela 4.

Diante da interpretação dos resultados, foi realizada a ANOVA por meio dos dois fatores de estudo: ajuste do $\mathrm{pH}$ e concentração $\mathrm{MPC} / \mathrm{WPC}$, verificando assim cada fator isolado e a interação entre os mesmos. Desse modo, foram obtidas três fontes de variação:

Tabela 2 - Análises físico-químicas das diferentes proporções de concentrados proteicos de leite e de soro (média \pm desvio padrão)

\begin{tabular}{|c|c|c|c|c|}
\hline Análises & $\begin{array}{l}100 \% \\
\text { WPC }\end{array}$ & $\begin{array}{c}50 \% \mathrm{WPC} / \\
50 \% \mathrm{MPC}\end{array}$ & $\begin{array}{l}25 \% \mathrm{WPC} / \\
75 \% \mathrm{MPC}\end{array}$ & $100 \% \mathrm{MPC}$ \\
\hline Gorduras Totais (g.kg-1 $)$ & $16,0 \pm 5,0$ & $12,0 \pm 5,0$ & $10,0 \pm 5,0$ & $8,0 \pm 5,0$ \\
\hline Umidade $\left(\mathrm{g} \cdot \mathrm{kg}_{-}{ }^{1}\right)$ & $54,0 \pm 10,0$ & $52,5 \pm 10,0$ & $52,0 \pm 10,0$ & $51,0 \pm 10,0$ \\
\hline Proteína Total (g.kg- $\left.{ }^{1}\right)$ & $643,6 \pm 12,0$ & $648,3 \pm 14,0$ & $651,0 \pm 14,0$ & $652,9 \pm 14,0$ \\
\hline $\begin{array}{l}\text { Proteína na base } \\
\operatorname{seca}^{1}\left(\text { g.kg- }{ }^{1}\right)\end{array}$ & $680,0 \pm 12,0$ & $684,0 \pm 14,0$ & $688,0 \pm 14,0$ & $688,0 \pm 14,0$ \\
\hline $\operatorname{Lactose}^{1}\left(\right.$ g.kg- $\left.{ }^{1}\right)$ & $254,4 \pm 10,0$ & $175,1 \pm 8,0$ & $135,08 \pm 8,0$ & $95,7 \pm 10,0$ \\
\hline RMF (g.kg- $\left.{ }^{1}\right)$ & $32,0 \pm 3,0$ & $51,5 \pm 2,0$ & $61,0 \pm 3,0$ & $71,0 \pm 2,0$ \\
\hline $\mathrm{pH}$ & $6,30 \pm 0,04$ & $6,62 \pm 0,05$ & $6,80 \pm 0,04$ & $6,85 \pm 0,03$ \\
\hline
\end{tabular}

\footnotetext{
${ }^{1}$ valores calculados
} 


\begin{tabular}{|c|c|c|c|c|c|c|}
\hline & \multirow{3}{*}{$\begin{array}{l}0 \\
\vdots \\
\vdots \\
o \\
o\end{array}$} & $\stackrel{m}{H}$ & $\begin{array}{l}0 \\
\hat{i} \\
+1 \\
\hat{i}\end{array}$ & $\begin{array}{l}3 \\
0 \\
+1 \\
\infty \\
0 \\
\hat{n}\end{array}$ & $\begin{array}{l}\overrightarrow{0} \\
+1 \\
0 \\
=\end{array}$ & $\begin{array}{l}7 \\
0 \\
+1 \\
6 \\
\text { in }\end{array}$ \\
\hline & & $\stackrel{N}{H}$ & $\begin{array}{l}0 \\
\hat{i} \\
+1 \\
0 \\
\hat{i}\end{array}$ & $\begin{array}{l}m \\
0 \\
+1 \\
12 \\
\hat{n}^{n}\end{array}$ & $\begin{array}{l}1 \\
0 \\
+1 \\
0 \\
=\end{array}$ & \begin{tabular}{l} 
No \\
+1 \\
+1 \\
$\infty$ \\
\multirow{2}{n}{}
\end{tabular} \\
\hline & & $\vec{E}$ & $\begin{array}{l}\hat{0} \\
\hat{i} \\
+1 \\
\hat{0} \\
\vec{i}\end{array}$ & $\begin{array}{l}n \\
0 \\
+1 \\
0 \\
0 \\
\hat{n}\end{array}$ & $\begin{array}{l}0 \\
0 \\
+1 \\
0 \\
= \\
=\end{array}$ & $\begin{array}{l}\text { Jै } \\
+ \\
\text { ปै }\end{array}$ \\
\hline & \multirow{3}{*}{ 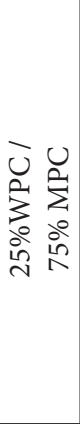 } & $\tilde{H}$ & $\begin{array}{l}0 \\
\hat{7} \\
+1 \\
10 \\
2\end{array}$ & $\begin{array}{l}n \\
0 \\
+1 \\
0 \\
\hat{2} \\
\hat{n}\end{array}$ & $\begin{array}{l}n \\
0 \\
+1 \\
0 \\
= \\
=\end{array}$ & $\begin{array}{l}2 \\
2 \\
+ \\
0 \\
10\end{array}$ \\
\hline & & $\stackrel{N}{F}$ & $\begin{array}{l}0 \\
i \\
+1 \\
0 \\
0 \\
a\end{array}$ & $\begin{array}{l}+1 \\
0 \\
+1 \\
\infty \\
\infty \\
\hat{n}\end{array}$ & $\begin{array}{l}\overrightarrow{0} \\
+1 \\
0 \\
0 \\
=\end{array}$ & \\
\hline & & E & $\begin{array}{l}0 \\
\hat{i} \\
+1 \\
0 \\
\hat{i}\end{array}$ & $\begin{array}{l}m \\
0 \\
+1 \\
0 \\
0 \\
i n\end{array}$ & $\begin{array}{l}1 \\
0 \\
+1 \\
0 \\
= \\
=\end{array}$ & \\
\hline & \multirow{3}{*}{ 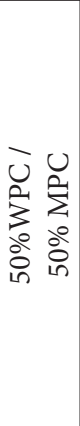 } & $\tilde{H}$ & $\begin{array}{l}\stackrel{0}{i} \\
+1 \\
\hat{0} \\
\vec{i}\end{array}$ & $\begin{array}{l}m \\
0 \\
+1 \\
i n \\
\hat{n}\end{array}$ & $\begin{array}{l}\overrightarrow{0} \\
+1 \\
0 \\
=\end{array}$ & $\begin{array}{l}+ \\
\text { t } \\
\text { L }\end{array}$ \\
\hline & & $\stackrel{N}{F}$ & $\begin{array}{l}\hat{0} \\
\stackrel{-1}{+1} \\
0 \\
\hat{\imath}\end{array}$ & $\begin{array}{l}+ \\
0 \\
+1 \\
0 \\
\hat{\sigma}\end{array}$ & $\begin{array}{l}3 \\
0 \\
+1 \\
0 \\
= \\
=\end{array}$ & $\frac{+}{\widehat{\gamma}}$ \\
\hline & & 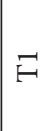 & $\begin{array}{l}0 \\
i \\
+1 \\
0 \\
0 \\
\hat{i}\end{array}$ & $\begin{array}{l}n \\
0 \\
+1 \\
10 \\
0 \\
0\end{array}$ & $\begin{array}{l}3 \\
0 \\
+1 \\
0 \\
= \\
=\end{array}$ & 7 \\
\hline 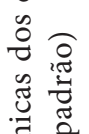 & \multirow{3}{*}{$\begin{array}{l}0 \\
3 \\
\vdots \\
0\end{array}$} & $\stackrel{m}{H}$ & $\begin{array}{l}0 \\
\hat{+1} \\
+1 \\
0 \\
\hat{i}\end{array}$ & $\begin{array}{l}+ \\
0 \\
+1 \\
0 \\
0 \\
0\end{array}$ & $\begin{array}{l}2 \\
0 \\
+1 \\
0 \\
=\end{array}$ & 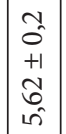 \\
\hline $\begin{array}{l}\frac{0}{1} \\
\frac{0}{0} \\
\frac{0}{0} \\
+1\end{array}$ & & $\stackrel{N}{F}$ & $\begin{array}{l}0 \\
i \\
+1 \\
0 \\
\hat{i}\end{array}$ & $\begin{array}{l}n \\
0 \\
+1 \\
0 \\
0 \\
0\end{array}$ & $\begin{array}{l}\overrightarrow{0} \\
+1 \\
0 \\
=\end{array}$ & $\mid$\begin{tabular}{l}
+1 \\
\multirow{Z}{*}{} \\
$\sigma$
\end{tabular} \\
\hline$\stackrel{\Xi}{\Xi}$ & & $\vec{F}$ & $\begin{array}{l}0 \\
i \\
+1 \\
0 \\
\hat{i}\end{array}$ & $\begin{array}{l}+1 \\
0 \\
+1 \\
\infty \\
\infty \\
\infty \\
i n\end{array}$ & $\begin{array}{l}2 \\
0 \\
+1 \\
y \\
=\end{array}$ & $\begin{array}{l}+ \\
0 \\
1 \\
\text { in }\end{array}$ \\
\hline \begin{tabular}{l}
\multirow{N}{*}{} \\
$\infty$ \\
0 \\
0
\end{tabular} & 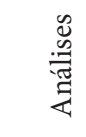 & & 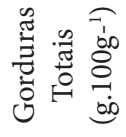 & 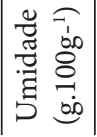 & 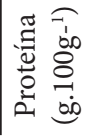 & \\
\hline
\end{tabular}


ajuste do $\mathrm{pH}$, concentração MPC/WPC e a interação ajuste do $\mathrm{pH}$ x concentração MPC/ WPC, que serão analisados para cada atributo avaliado na análise de textura.

\section{Dureza}

Para o atributo dureza, houve diferença significativa $(\mathrm{p}<0,05)$ em relação ao ajuste de pH (Tabela 5) e em relação a proporção de WPC/MPC. Já em relação à interação entre estes dois fatores, não foi observado diferença significativa $(p>0,05)$.

De acordo com a Tabela 5, houve uma diferença significativa na dureza $(\mathrm{p}<0,05)$ no tratamento sem ajuste de $\mathrm{pH}(\mathrm{pH} \mathrm{6,2 \pm 0,1)}$ para os tratamentos onde houve algum tipo de ajuste $(5,6 \pm 0,1)$.
Tabela 5 - Valores médios de dureza em relação ao $\mathrm{pH}$ nas diferentes proporção de WPC/MPC dos queijos processados mantidos sob refrigeração a $5{ }^{\circ} \mathrm{C}$ e analisados após 24 horas

\begin{tabular}{cc}
\hline Tratamentos & Médias \\
\hline Ajuste $\mathrm{pH}$ Inicial & $1103,56^{\mathrm{a}}$ \\
Ajuste $\mathrm{pH}$ Final & $1138,62^{\mathrm{a}}$ \\
Sem ajuste $\mathrm{pH}$ & $1380,50^{\mathrm{b}}$
\end{tabular}

*Letras iguais não diferem significativamente pelo teste de Tukey ao nível de 5\% de probabilidade.

Com relação a influência da proporção de WPC/MPC no parâmetro dureza, percebese uma redução no valor deste até o nível de $40 \% \mathrm{WPC} / 60 \% \mathrm{MPC}$ (Figura 2). O maior valor

Tabela 4 - Perfil de textura nos diferentes tratamentos de queijos processados mantidos sob refrigeração a $5{ }^{\circ} \mathrm{C}$ e analisados após 24 horas

\begin{tabular}{|c|c|c|c|c|}
\hline \multicolumn{5}{|c|}{ Níveis } \\
\hline \multicolumn{5}{|c|}{ Tratamentos } \\
\hline Sem ajuste $\mathrm{pH}(\mathrm{pH} 6,2 \pm 0,1)$ & $\begin{array}{l}100 \% \\
\mathrm{MPC}\end{array}$ & $75 \% / 25 \%$ & $50 \% / 50 \%$ & $\begin{array}{l}100 \% \\
\text { WPC }\end{array}$ \\
\hline Dureza $(\mathrm{g})$ & $1689 \pm 157$ & $940 \pm 116$ & $1007 \pm 46$ & $1887 \pm 44$ \\
\hline Adesividade (mJ) & $51 \pm 3$ & $21 \pm 1$ & $21 \pm 1$ & $0,2 \pm 0,02$ \\
\hline Elasticidade $(\mathrm{mm})$ & $14 \pm 2$ & $11 \pm 1$ & $10 \pm 1$ & $8 \pm 0,2$ \\
\hline \multicolumn{5}{|c|}{ Níveis } \\
\hline \multicolumn{5}{|c|}{ Tratamentos } \\
\hline Ajuste de $\mathrm{pH}$ inicial (pH $5,6 \pm 0,1)$ & $\begin{array}{l}100 \% \\
\mathrm{MPC}\end{array}$ & $75 \% / 25 \%$ & $50 \% / 50 \%$ & $\begin{array}{l}100 \% \\
\text { WPC }\end{array}$ \\
\hline Dureza $(g)$ & $1066 \pm 119$ & $758 \pm 1$ & $1006 \pm 36$ & $1585 \pm 195$ \\
\hline Adesividade (mJ) & $25 \pm 3$ & $23 \pm 3$ & $14 \pm 0,9$ & $0,2 \pm 0,05$ \\
\hline Elasticidade (mm) & $12 \pm 1$ & $10 \pm 0,5$ & $8 \pm 1,6$ & $7 \pm 0,35$ \\
\hline \multicolumn{5}{|c|}{ Níveis } \\
\hline \multicolumn{5}{|c|}{ Tratamentos } \\
\hline Ajuste de $\mathrm{pH}$ final $(\mathrm{pH} 5,6 \pm 0,1)$ & $\begin{array}{l}100 \% \\
\mathrm{MPC}\end{array}$ & $75 \% / 25 \%$ & $50 \% / 50 \%$ & $\begin{array}{l}100 \% \\
\text { WPC }\end{array}$ \\
\hline Dureza (g) & $1079 \pm 12$ & $781 \pm 1$ & $1010 \pm 68$ & $1685 \pm 155$ \\
\hline Adesividade (mJ) & $37 \pm 9$ & $21 \pm 2$ & $12 \pm 3,5$ & 0,2 \\
\hline Elasticidade (mm) & $13 \pm 1,4$ & $11 \pm 0,4$ & $7 \pm 1,0$ & $7 \pm 0,1$ \\
\hline
\end{tabular}


foi atingido quando o nível de WPC alcança $100 \%$ dentro da proporção de concentrado proteico utilizado.

\section{Adesividade}

Em relação ao atributo adesividade, houve diferença significativa $(\mathrm{p}<0,05) \mathrm{em}$ relação ao ajuste de $\mathrm{pH}$, proporção de WPC/ MPC e interação entre estes dois fatores.

Para a visualização da tendência dos dados, tem-se a regressão do desdobramento do ajuste do $\mathrm{pH}$ dentro da proporção WPC/ MPC. Desta maneira, pode-se visualizar a influencia do $\mathrm{pH}$ e da concentração de WPC/ MPC na adesividade (Figura 3).

Para melhor visualização da diferença entre os tratamentos, realizou-se o teste de médias (Tabela 6), visando facilitar a obtenção do grau de significância das variações.
Assim, analisando a primeira coluna, quando não houve ajuste de $\mathrm{pH}$, a concentração do WPC influenciou na adesividade, sendo que na concentração de $0 \%$ de WPC a adesividade foi maior, seguida pela concentração de $25 \%$, $50 \%$ e $100 \%$ respectivamente, variação esta mantida nas demais colunas. Quando o ajuste de $\mathrm{pH}$ foi realizado no momento inicial da produção somente foi observado diferença significativa em relação ao tratamento com $100 \%$ de WPC, sendo este o menor valor de adesividade entre os tratamentos. Avaliando o ajuste de $\mathrm{pH}$ no momento final da fabricação, observa-se a mesma diferença no tratamento sem ajuste de $\mathrm{pH}$.

Já analisando a primeira linha, na concentração de $0 \%$ de WPC, o ajuste do $\mathrm{pH}$ influenciou na adesividade. Quando não houve ajuste de $\mathrm{pH}$, a adesividade foi maior, do que quando foi realizado ajuste final, e esta por

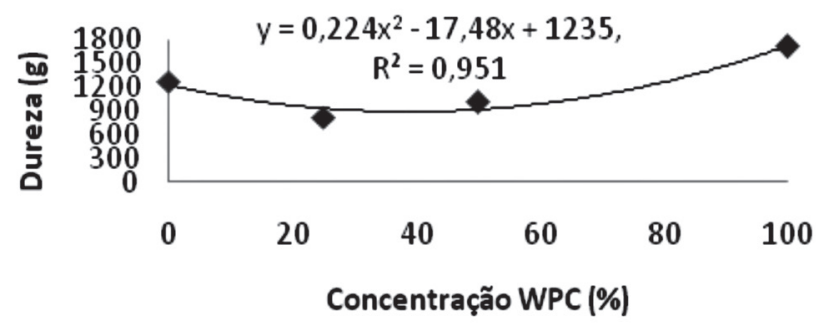

Figura 2 - Efeito da dureza nos queijos processados em relação à concentração de WPC

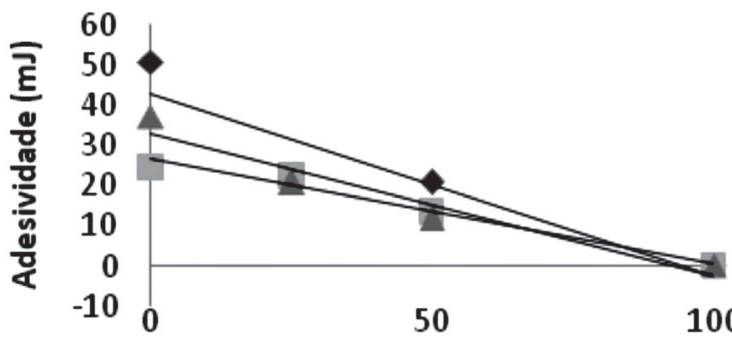

$y=-0,4544 x+43,106$

$R^{2}=0,8568$

Sem ajuste $\mathrm{pH}$

Ajuste Inicial pH $\mathrm{\gamma}=-0,2576 \mathrm{x}+26,536$

$\triangle$ Ajuste Final pH

$y=-0,3559 x+33,25$

$R^{2}=0,9373$

\section{Concentração WPC}

Figura 3 - Efeito da adesividade nos queijos processados em relação à concentração de WPC e o ajuste do $\mathrm{pH}$ 
sua vez foi maior que quando executado ajuste inicial. Nas demais proporções de WPC/MPC não houve diferenças significativas entre os resultados para o parâmetro adesividade $(\mathrm{p}>0,05)$.

\section{Elasticidade}

Em relação ao atributo elasticidade, houve diferença significativa $(\mathrm{p}<0,05)$ apenas em relação à proporção de WPC/MPC. Já em relação ao ajuste do $\mathrm{pH}$ e em relação à interação entre estes dois fatores não foi observado diferença significativa.

Assim, de acordo com as diferenças observadas tem-se a análise de regressão apresentada na Figura 4.

De acordo com o gráfico de regressão, é possível observar a redução na elasticidade do produto à medida que se aumenta a concentração de WPC na formulação do produto.

\section{Diagramas de otimização da utilização de concentrados proteicos}

De acordo com os dados apresentados até então, é possível apresentar a Tabela 7 com o resumo da influência de cada tipo de concentrado proteico nos atributos analisados nos queijos processados cremoso no $\mathrm{pH} 5,6 \pm 0,1$.

Na visualização quanto maior o número de sinais positivo $(+)$ maior o impacto deste concentrado na avaliação realizada.

Em relação à interferência da variação do $\mathrm{pH}$ nas características de textura dos queijos processados cremosos observa-se diferença significativa da alteração do valor de 5,6 para 6,3, nas características de dureza e

Tabela 6 - Valores médios de adesividade nos queijos processados estocados sob refrigeração a $5{ }^{\circ} \mathrm{C}$ e analisados após 24 horas

\begin{tabular}{cccc}
\hline & \multicolumn{3}{c}{ Ajuste $\mathrm{pH}$} \\
\hline $\begin{array}{c}\text { Concentração } \\
\text { WPC }\end{array}$ & $\begin{array}{c}\text { Sem } \\
\text { ajuste }\end{array}$ & $\begin{array}{c}\text { Ajuste } \\
\text { Inicial }\end{array}$ & $\begin{array}{c}\text { Ajuste } \\
\text { final }\end{array}$ \\
\hline 0 & $51,08^{\mathrm{Ac}}$ & $24,75^{\mathrm{Bb}}$ & $37,42^{\mathrm{Cc}}$ \\
25 & $20,86^{\mathrm{Ab}}$ & $22,52^{\mathrm{Ab}}$ & $21,09^{\mathrm{Ab}}$ \\
50 & $20,77^{\mathrm{Ab}}$ & $13,59^{\mathrm{Ab}}$ & $13,01^{\mathrm{Ab}}$ \\
100 & $0,20^{\mathrm{Aa}}$ & $0,20^{\mathrm{Aa}}$ & $0,20^{\mathrm{Aa}}$ \\
\hline
\end{tabular}

*Médias seguidas pela mesma letra maiúscula, na linha, e minúscula, na coluna, não diferem significativamente entre si pelo teste de Tuckey $(\mathrm{p}<0,05)$

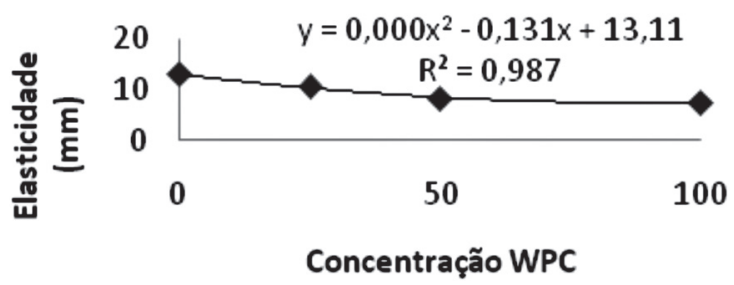

Figura 4 - Efeito da elasticidade nos queijos processados em relação à concentração de WPC 
adesividade. Essa diferença pode ser explicada pela diferença do nível de desnaturação térmica e interação proteica ocorrida nestas diferentes proporções de concentrados proteicos, ou seja, nas diferentes relações de caseínas/soroproteínas presentes no produto. Além deste fator, pode-se citar também dentro desta aplicação a possível interferência dos sais citrato de sódio e tripolifosfato de sódio nestes diferentes valores de $\mathrm{pH}$.

Em estudo apresentado por Anema (2008), verifica-se que o nível de $\kappa$-caseína $(\kappa-\mathrm{CN})$ no soro incrementa aproximadamente 10 a $20 \%$ durante os primeiros 5 minutos de aquecimento, em $\mathrm{pH} 6,5$, com pequena mudança durante o restante do aquecimento. Quando foi realizado a alteração do $\mathrm{pH}$ de 6,7 e 6,9, pode-se observar, respectivamente, que, aproximadamente, 30 e $40 \%$ da $\kappa-\mathrm{CN}$ estavam no soro durante os primeiros 5 minutos. $\mathrm{O}$ incremento da $\kappa-\mathrm{CN}$ na fase soro no aquecimento em $\mathrm{pH}$ 6,7 e 6,9 foi acompanhada por algum incremento no nível de $\alpha_{\mathrm{s}}$-caseína e $\beta$-caseína. Em outra avaliação neste mesmo estudo, pode-se observar que em pH 6,5, o nível de soroproteínas decresceu com o aumento da temperatura de modo que aproximadamente $40 \%$ das soroproteínas se mantiveram no soro após aquecimento à $90{ }^{\circ} \mathrm{C}$. Já quando foi realizado o aumento do $\mathrm{pH}$ no aquecimento, observou-se que $70 \%$ e $90 \%$ das soroproteínas se mantiveram no soro em $\mathrm{pH}$ de 6,7 e 6,9 , respectivamente. $\mathrm{O}$ tratamento térmico a $90^{\circ} \mathrm{C}$, aproximadamente $90 \%$ das soroproteínas foram desnaturadas em todos os $\mathrm{pH}$.

A interação entre as soroproteínas desnaturadas e $\kappa-\mathrm{CN}$ formam pequenos agregados na fase soro (GUYOMARC'H et al. 2003; RODRIGUEZ DEL ANGEL; DALGLEISH, 2006; ANEMA, 2007), enquanto que a interação entre soroproteínas, na ausência de caseínas, podem formar grandes agregados na força iônica encontrada no leite (SCHORSCH et al. 2001). Sabe-se que a adição de caseínas, particularmente $\kappa-\mathrm{CN}$ as soroproteínas antes do tratamento térmico limita o tamanho dos agregados (MCKENZIE et ai. 1971), o que pode sugerir uma reação preferencial entre $\kappa-\mathrm{CN}$ e as soroproteínas desnaturadas (particularmente $\beta$-lactoglobulina) sobre as interações entre as diferentes soroproteínas.

As pontes dissulfeto com a $\kappa-\mathrm{CN}$ estão localizadas no $\mathrm{N}$-terminal da região hidrofóbica (para- $\kappa-\mathrm{CN}$ ), enquanto que o C-terminal é altamente carregado e hidrofílico (caseinomacropeptídeo). O C-terminal não interage com facilidade e age, na verdade, como uma camada estabilizadora quando associado com a superfície das partículas coloidais, tais como micelas de caseínas (WALSTRA, 1999). Portanto, em vez de uma interação preferencial entre $\kappa-\mathrm{CN}$ e as soroproteínas desnaturadas, é provável

Tabela 7 - Diagrama de otimização da utilização de concentrados proteicos para processamento de Queijos Processados

\begin{tabular}{|c|c|c|c|c|c|c|}
\hline \multirow{3}{*}{$\begin{array}{c}\text { Diagrama de otimização } \\
\text { da utilização de concentrados } \\
\text { proteicos para } \\
\text { processamento de } \\
\text { Queijos Processados }\end{array}$} & \multicolumn{4}{|c|}{ pH 5,6 $\pm 0,1$} & \multicolumn{2}{|c|}{$\begin{array}{c}\text { Comparativo entre } \\
\text { valores de } \mathrm{pH}\end{array}$} \\
\hline & MPC & \multicolumn{2}{|c|}{ WPC / MPC } & WPC & \multirow{2}{*}{$\mathrm{pH} 5,6$} & \multirow{2}{*}{$\mathrm{pH} 6,3$} \\
\hline & 100 & $25 / 75$ & $50 / 50$ & 100 & & \\
\hline Dureza & +++ & + & ++ & ++++ & + & ++ \\
\hline Adesividade & ++++ & +++ & ++ & + & + & ++ \\
\hline Elasticidade & ++++ & +++ & ++ & + & ++ & ++ \\
\hline
\end{tabular}


que a incorporação de $\kappa$-CN nos agregados atua como uma cadeia terminal, limitando o tamanho e estabilizando-os.

Van Dender et al. (2005), verificaram que com o aumento do teor de extrato seco desengordurado (ESD) houve um aumento da firmeza, na adesividade e na gomosidade de queijos processados, ao passo que a elasticidade apresentou uma diminuição. Esses resultados também foram obtidos por Gupta et al. (1992), que ao avaliarem o efeito da adição de WPC na firmeza de queijos processados constataram que o aumento do teor de ESD ocasionado pela adição de WPC resultou em uma maior firmeza do produto. Resultados semelhantes foram obtidos por Olson et al (1961), que verificaram um aumento dos valores de firmeza de queijo processado em que foram adicionados leite em pó desnatado e soro em pó com intuito de aumentar o teor de extrato seco desengordurado de queijos processados. Além disso, esses autores observaram que a elasticidade dos produtos diminuiu com o aumento no teor de proteínas, o que confirma o efeito da desnaturação e interação proteica durante o processamento nas características de textura deste tipo de queijo.

Assim, a obtenção de maior dureza no tratamento com maior proporção de WPC pode ser justificado pela diferença no tamanho dos agregados entre soroproteínas e/ou $\kappa-\mathrm{CN}$-soroproteínas e o maior grau de desnaturação em maiores valores de $\mathrm{pH}$. Já os maiores valores obtidos para elasticidade e adesividade nos tratamentos com 100\% MPC são influenciados pelo menor concentração de soroproteínas desnaturadas e em interação com a $\kappa-\mathrm{CN}$ após o processamento térmico.

\section{CONCLUSÕES}

As variações nas proporções de concentrado protéico de soro e concentrado protéico de leite alteram a dureza, elasticidade e adesividade de queijos processados. No parâmetro dureza, a influência é maior, quanto maior o teor de WPC. Para a adesividade e a elasticidade dos queijos processados, o maior teor de MPC causa maior impacto nesses parâmetros de textura. A alteração do $\mathrm{pH}$ modifica as características de dureza e adesividade dos queijos processados cremosos que utilizam concentrados proteicos.

\section{REFERÊNCIAS}

ANEMA, S. G.; LI, Y. Effect of $\mathrm{pH}$ on the association of denatured whey proteins with the casein micelles in heated reconstituted skim milk. Journal of Agricultural and Food Chemistry, v. 51, n. 6, p. 1640-1646, 2003.

ANEMA, S. G. Role of $\kappa$-casein in the association of denatured whey proteins with casein micelles in heated reconstituted skim milk. Journal of Agricultural and Food Chemistry, v. 55, n. 9, p. 3635-3642, 2007.

ANEMA, S. G. On heating milk $\kappa$-casein from the casein micelles can precede interactions with the denatured whey proteins. Journal of Dairy Research, v. 75, n. 4, p. 415-421, 2008.

A S S OCIATION OF OFFICIA L ANALYTICAL CHEMISTS (AOAC). Official Methods of Analysis of AOAC International. 18th ed. Gaithersburg: AOAC International, 2005.

BRASIL. Ministério da Agricultura e do Abastecimento. Departamento de Inspeção de Produtos de Origem Animal. Portaria $\mathrm{n}^{\circ} 359$ de 04 de setembro de 1997. Regulamento Técnico para Fixação de Identidade e Qualidade do Requeijão Cremoso ou Requesón. Diário Oficial da República Federativa do Brasil. Brasília, 08 set. 1997. Seção 1, p. 19690. 
DANNENBERG, F.; KESSLER, H. G. Reaction kinetics of the denaturation of whey proteins in milk. Journal of Food Science, v. 53, n. 1, p. 258-263, 1998.

FERREIRA, D. F. Análises estatísticas por meio do SISVAR para Windows versão 4.0. In: REUNIÃO ANUAL DA REGIÃO BRASILEIRA DA SOCIEDADE INTERNACIONAL DE BIOMETRIA (RBRAS), 45., 2000, São Carlos. Anais... São Carlos: UFSCar, 2000. p. 255-258.

GUYOMARC'H, F.; LAW, A. J. R.; DALGLEISH, D. G. Formation of soluble and micelle-bound protein aggregates in heated milk. Journal of Agricultural and Food Chemistry, v. 51, n. 16, p. 4652-4660, 2003.

GUPTA, V. K.; REUTER, H. Processed cheese foods with added whey protein concentrates. Lait, v. 72, n. 2, p. 201-212, 1992.

MCKENZIE, G. H.; NORTON, R. S.; SAWYER, W. H. Heat-induced interaction of $\beta$-lactoglobulin and $\kappa$-casein. Journal of Dairy Research, v. 38, n. 3, p. 343-351, 1971.

OLSON, N. F.; PRICE, W. V. Composition and bacterial growth as factors affecting the body of pasteurized process cheese spread.
Journal of Dairy Science, v. 44, n. 8, p. 1394-1404, 1961.

RODRIGUEZ DEL ANGEL, C.; DALGLEISH, D. G. Structure and some properties of soluble protein complexes formed by the heating of reconstituted skim milk powder. Food Research International, v. 39, n. 4, p. 472-479, 2006.

SINGH, H. Protein interactions and functionality of milk protein products. In: CORREDIG, M. ed. Dairy-derived ingredients: food and nutraceutical uses. Cambridge: Woodhead, 2009. cap. 25, p. 644-674.

SCHORSCH C. et al. Gelation of casein-whey mixtures: effects of heating whey proteins alone or in the presence of casein micelles. Journal of Dairy Research, v. 68, n. 3, p. 471-481, 2001.

VAN DENDER, A. G. F. et al. Correlação entre a composição físico-química e os parâmetros da análise de perfil de textura (TPA) de queijos processados. Revista do Instituo de Laticínios Cândido Tostes, v. 60, n. 345, p. 397-403, 2005.

WALSTRA, P. Casein sub-micelles : do they exist? International Dairy Journal, v. 9, n. 3-6, p. 189-192, 1999. 